\title{
Article \\ Experimental Analysis and Prediction Model of Milling-Induced Residual Stress of Aeronautical Aluminum Alloys
}

\author{
Shouhua $\mathrm{Yi}^{1,2}{ }^{1}$, Yunxin $\mathrm{Wu}{ }^{1,3,4}$, Hai Gong $1,3,4, * \mathbb{C}$, Chenxi Peng ${ }^{3}$ and Yongbiao $\mathrm{He}^{3}$ \\ 1 College of Mechanical and Electrical Engineering, Central South University, Changsha 410083, China; \\ yishouhua@hnu.edu.cn (S.Y.); wuyunxin@csu.edu.cn (Y.W.) \\ 2 Modern Engineering Training Centre, Hunan University, Changsha 410082, China \\ 3 Light Alloy Research Institute, Central South University, Changsha 410083, China; \\ pengchenxi2021@163.com (C.P.); hyb88880314@126.com (Y.H.) \\ 4 State Key Laboratory of High Performance Complex Manufacturing, Central South University, \\ Changsha 410083, China \\ * Correspondence: gonghai@csu.edu.cn
}

Citation: Yi, S.; Wu, Y.; Gong, H.; Peng, C.; He, Y. Experimental Analysis and Prediction Model of Milling-Induced Residual Stress of Aeronautical Aluminum Alloys. Appl. Sci. 2021, 11, 5881. https://doi.org/ 10.3390/app11135881

Received: 11 May 2021

Accepted: 22 June 2021

Published: 24 June 2021

Publisher's Note: MDPI stays neutral with regard to jurisdictional claims in published maps and institutional affiliations.

Copyright: (C) 2021 by the authors Licensee MDPI, Basel, Switzerland. This article is an open access article distributed under the terms and conditions of the Creative Commons Attribution (CC BY) license (https:// creativecommons.org/licenses/by/ $4.0 /)$
Featured Application: This paper proposes a prediction model for milling residual stress based on a BP neural network. It aims to provide basic data calculation tools for analyzing the influence of milling residual stress on workpiece deformation, crack resistance, fatigue life, and corrosion resistance. Unlike traditional forecasting models, the prediction model is based on actual machining conditions. The prediction model contains the influence of various hidden factors, so it is closer to actual production. Additionally, the proposed model has a high prediction accuracy because of the strong nonlinear mapping ability of the BP neural network.

Abstract: Aeronautical thin-walled frame workpieces are usually obtained by milling aluminum alloy plates. The residual stress within the workpiece has a significant influence on the deformation due to the relatively low rigidity of the workpiece. To accurately predict the milling-induced residual stress, this paper describes an orthogonal experiment for milling 7075 aluminum alloy plates. The milling-induced residual stress at different surface depths of the workpiece, without initial stress, is obtained. The influence of the milling parameters on the residual stress is revealed. The parameters include milling speed, feed per tooth, milling width, and cutting depth. The experimental results show that the residual stress depth in the workpiece surface is within $0.12 \mathrm{~mm}$, and the residual stress depth of the end milling is slightly greater than that of the side milling. The calculation models of residual stress and milling parameters for two milling methods are formulated based on regression analysis, and the sensitivity coefficients of parameters to residual stress are calculated. The residual stress prediction model for milling 7075 aluminum alloy plates is proposed based on a back-propagation neural network and genetic algorithm. The findings suggest that the proposed model has a high accuracy, and the prediction error is between 0-14 MPa. It provides basic data for machining deformation prediction of aluminum alloy thin-walled workpieces, which has significant application potential.

Keywords: aeronautical aluminum alloy; residual stress; prediction model; back-propagation neural network

\section{Introduction}

Aeronautical aluminum alloy has a high specific strength, as well as excellent mechanical and machining properties. As an ideal structural material, it is widely used to manufacture aeronautical workpieces [1-5]. Thin-walled frame structures machined from aluminum alloy plates is the first choice for aeronautical workpieces to improve production efficiency and reduce product weight, assembly time, and production costs [6-8]. However, 
material removal of a thin-walled frame workpiece is large, and the workpiece stiffness after machining is low. During the machining process, the internal residual stress of the plate changes in a complicated way, which causes the workpiece to warp or twist after machining. The workpiece deformation causes a high rejection rate or additional correction procedures, which significantly increases production costs and reduces production efficiency [9-11]. The cutting-induced residual stress is an essential factor affecting workpiece deformation and accuracy stability [12]. As the residual stress increases, the thin-walled workpiece deformation increases [13]. In addition, the cutting-induced residual stress affects the service life and performance of the workpiece [14,15].

Residual stress is mainly caused by the combined effects of cutting force and cutting heat during the machining process [16]. Scholars have carried out a great deal of research on the machining-induced residual stress of structural parts. Shan et al. [17] proposed an improved prediction model for the residual stress of an orthogonal cutting process, considering the mechanical and thermal stress based on contact mechanics, the JohnsonCook constitutive model, and the slip line theory. Starting from the geometric parameters of the milling cutter, Shen et al. [18] created a finite element model to investigate the influence of the cutting edge shape on the residual stress distribution in the machined surface. Ji et al. [19] studied the residual stress distribution in square pocket milling of 2219 aluminum alloy. They suggested that the axial cutting depth is the most critical factor influencing the residual stress distribution of the machined pocket surface. As the axial cutting depth increased, the tensile stress increased. The altered feed rate and radial cutting depth slightly affected the residual stress distribution and the average value. Liu et al. [20] pointed out that the plastic deformation caused by the cutting force is the dominant factor in the residual stress in ultra-precision machining 2024 aluminum alloy with a single crystal diamond tool. Salvati and Korsunsky [21] reconstructed the residual stress caused by the surface treatment based on the finite element method. Feature simplification reduces the amount of calculation during preprocessing by the finite element software. Meng et al. [22] investigated the effects of prestress on surface residual stress through milling experiments. Zhang et al. [23] studied the impact of milling width on surface residual stress using Al5Si aluminum alloy. Further, they explored the influence of milling thickness on the tensile anisotropy of hybrid wire arc additive-milling subtractive manufacturing. Xiong et al. [24] analyzed the residual stress of in situ milling of TiB2/7050Al metal matrix composites. They found that cutting temperature played a significant role in residual stress through comparative research. Huang et al. [25] proposed an analytical method for residual stress prediction in dynamic orthogonal cutting and formulated a dynamic orthogonal cutting mechanistic model considering the effect of cutting edge indentation. Based on plastic strain calculation and the inclusion theory, they formulated an analytical residual stress solution of the plastic strain distributed in the half-plane. Then, they predicted two-dimensional residual stress distribution in non-relaxation dynamic cutting and performed a dynamic cutting orthogonal experiment to verify the prediction results. Cheng et al. [26] studied surface residual stress under different cutting parameters and machining characteristics. They proposed a new method based on Gaussian process regression for predicting machining-induced surface residual stress, which was verified through comparison to other machine learning algorithms. Andrey et al. [27] studied the effect of repeated stress on hard milling using $3 \mathrm{D}$ finite element simulations. They investigated the formation of stresses at variable tooth feeds with a constant cutting speed and depth, and determined the development of material modifications (residual stresses) due to multiple stresses. Zhou et al. [28] presented an analytical model of residual stress generation in complex surface milling. Milling-introduced mechanical stress was determined according to the contact mechanics and the geometric transformation in the workpiece. The residual stress was estimated using an elastic-plastic model and a relaxation procedure. Additionally, the proposed model was verified through a milling experiment.

Cutting-induced residual stress causes workpiece deformation, significantly affecting performance. For example, the negative effect of tensile residual stress was revealed in 
terms of crack resistance, fatigue life, and corrosion resistance. Reducing residual stress can enhance material performance [29]. Therefore, it is necessary to measure and optimize residual stress distribution to evaluate the residual stress state in the machined surface, control the workpiece deformation, and improve its performance. For the characteristics of cutting-induced residual stress, the most widely used measurement technology is $X$-ray diffraction. The accuracy of this method reaches $\pm 10 \mathrm{MPa}$, and it has become the international standard method for surface residual stress measurement. However, limited by the X-ray penetration ability, it is difficult to measure the residual stress distribution directly [30]. Moreover, using the measurement method to adjust the machining parameters for the required residual stress results in high time and economic costs. Previous studies on cutting-induced residual stress mainly used analytical methods, finite element methods, and experimental methods. They explored the influence law and prediction model of cutting force, cutting heat, tool geometric sizes, and some cutting parameters on residual stress under dry cutting conditions and orthogonal cutting process. However, the research on the influence law and prediction model of various factors on residual stress under wet cutting conditions and non-orthogonal cutting process is rarely involved. Milling aluminum alloy is generally under cooling conditions, which is non-orthogonal cutting. The simulation method is computationally intensive and time-consuming. The experimental method is time-consuming, laborious, and costly. In addition, it is necessary to repeatedly establish simulation models and implement experimental verification for parts with different characteristics and machining parameters.

Given the above issues, it is of engineering significance to study residual stress distribution and the prediction model under actual milling conditions. This paper takes 7075 aluminum alloy as the research object and performs experimental research on millinginduced residual stress. Firstly, the influence of milling parameters (e.g., milling speed, feed per tooth, milling width, and cutting depth) on the residual stress in end milling and side milling under a wet cutting condition is comparatively studied. Secondly, a back-propagation (BP) neural network with a strong nonlinear mapping ability is used to formulate the residual stress prediction model of milling aeronautical aluminum alloy based on the experimental data. Finally, the accuracy of the proposed prediction model is verified by experiments.

\section{Milling-Induced Residual Stress Experiment of 7075 Aluminum Alloy}

\subsection{Design of the Experimental Study}

The experimental material was a 7075-T7451 aluminum alloy pre-stretched plate. To save the time of preparing the test pieces, a type of test piece with $100 \mathrm{~mm} \times 80 \mathrm{~mm} \times 40 \mathrm{~mm}$ was cut out from the plate for an end milling experiment. A total of five test pieces were milled by the bottom edge of an end mill. Each test piece was subjected to two milling experiments with two sets of milling parameters. Each milling experiment was also performed at a different position of the test piece. Another type of test piece with a size of $100 \mathrm{~mm} \times 40 \mathrm{~mm} \times 40 \mathrm{~mm}$ was prepared for the side milling experiment, i.e., milling with the circumferential edge of an end mill. There were nine test pieces in total, and each test piece was only subjected to a milling experiment with one set of milling parameters. The two milling methods are shown in Figure 1.

Although the residual stress of Al7075-T7451 plate is about $\pm 30 \mathrm{MPa}$, when it is superimposed with the milling stress, the milling stress cannot be distinguished. Therefore, before milling, the test pieces were subjected to stress relief annealing treatment to eliminate the influence of initial residual stress on the milling-induced residual stress. The temperature of annealing was about $350{ }^{\circ} \mathrm{C}$. The initial stress of the annealed test pieces was tested and found to be around $\pm 10 \mathrm{MPa}$, which can be regarded as a stress-free state.

The milling was carried out on a five-axis machining center of DMG-DMU-60monoBLOCK, and the primary parameters are listed in Table 1 . The milling adopted the Heye-M2Al 4-blade-alloy milling cutter with a diameter of $20 \mathrm{~mm}$, helix angle of $30^{\circ}$, rake angle of $15^{\circ}$, relief angle of $10^{\circ}$, and cutting edge of $50 \mathrm{~mm}$. 


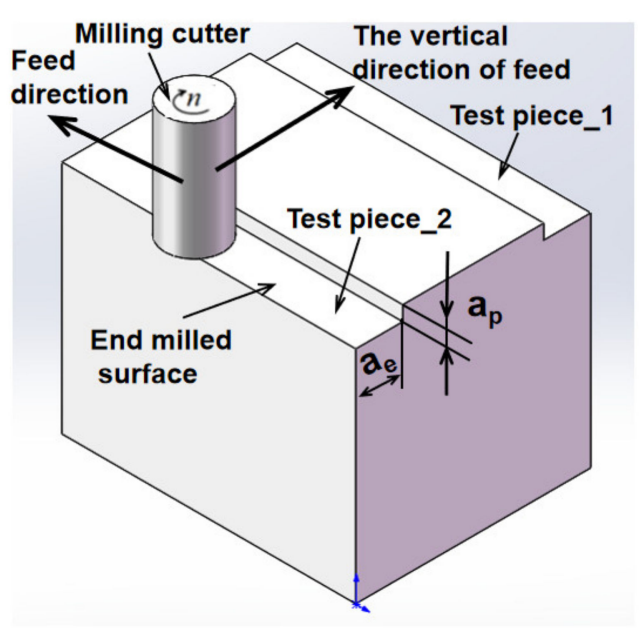

(a)

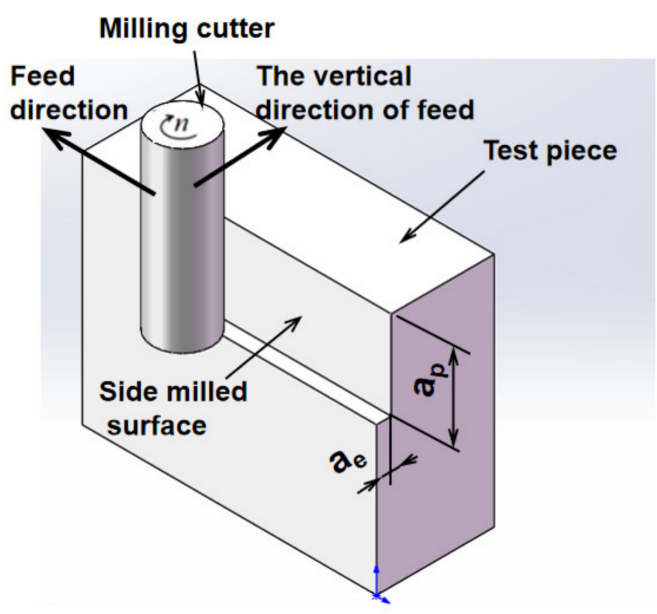

(b)

Figure 1. The end milling and side milling: (a) the end milling; (b) the side milling.

Table 1. The primary parameters of the five-axis machining center.

\begin{tabular}{cc}
\hline Parameters & Values \\
\hline Stroke $(\mathrm{mm})$ & $\mathrm{X}=630, \mathrm{Y}=560, \mathrm{Z}=560$ \\
B-axis swing angle $\left(^{\circ}\right)$ & $-120 \sim+30$ \\
Maximum spindle speed $(\mathrm{r} / \mathrm{min})$ & 12,000 \\
Maximum feed rate of linear axis $(\mathrm{mm} / \mathrm{min})$ & 30,000 \\
Positioning accuracy $(\mathrm{mm})$ & 0.006 \\
Control system & Heidenhain iTNC530 \\
\hline
\end{tabular}

Cutting oil was used to cool the tool during milling. The factors affecting the test piece deformation included milling speed, $\mathrm{v}_{c}$; feed per tooth, $\mathrm{f}_{\mathrm{z}}$; milling width, $\mathrm{a}_{\mathrm{e}}$; and cutting depth, $a_{p}$. Thus, a four-factor three-level orthogonal milling experiment was adopted. Taking into account the performance of the selected tool and the range of commonly used finishing milling parameters, we selected three milling speeds (i.e., $125.6 \mathrm{~m} / \mathrm{min}, 376.8 \mathrm{~m} / \mathrm{min}$, $628 \mathrm{~m} / \mathrm{min}$ ) and three levels of feed per tooth (i.e., $0.01 \mathrm{~mm} / \mathrm{z}, 0.025 \mathrm{~mm} / \mathrm{z}, 0.05 \mathrm{~mm} / \mathrm{z}$ ). For end milling, three milling depths (i.e., $0.5 \mathrm{~mm}, 1 \mathrm{~mm}, 1.5 \mathrm{~mm}$ ) and three milling widths (i.e., $10 \mathrm{~mm}, 15 \mathrm{~mm}, 20 \mathrm{~mm}$ ) were selected. For side milling, three milling depths (i.e., $15 \mathrm{~mm}, 25 \mathrm{~mm}, 35 \mathrm{~mm}$ ) and three milling widths (i.e., $0.2 \mathrm{~mm}, 0.6 \mathrm{~mm}, 1 \mathrm{~mm}$ ) were selected. The parameters of the end milling and side milling are presented in Tables 2 and 3.

Table 2. The parameters of the end milling experiment.

\begin{tabular}{|c|c|c|c|c|}
\hline Test Piece Number & $v_{c}(\mathrm{~m} / \mathrm{min})$ & $f_{z}(\mathrm{~mm})$ & $a_{p}(\mathrm{~mm})$ & $a_{e}(\mathrm{~mm})$ \\
\hline 1 & 125.6 & 0.01 & 0.5 & 10 \\
\hline 2 & 125.6 & 0.025 & 1 & 15 \\
\hline 3 & 125.6 & 0.05 & 1.5 & 20 \\
\hline 4 & 376.8 & 0.01 & 1 & 20 \\
\hline 5 & 376.8 & 0.025 & 1.5 & 10 \\
\hline 6 & 376.8 & 0.05 & 0.5 & 15 \\
\hline 7 & 628 & 0.01 & 1.5 & 15 \\
\hline 8 & 628 & 0.025 & 0.5 & 20 \\
\hline 9 & 628 & 0.05 & 1 & 10 \\
\hline
\end{tabular}

\subsection{Test Results of Milling-Induced Residual Stress}

The residual stress in the surface of the milled test pieces was measured by X-ray diffraction. The test instrument was a XSTRESS-3000 residual stress analyzer made in Finland, with an accuracy of $\pm 10 \mathrm{MPa}$. The parameters of the X-ray diffractometer are 
shown in Table 4. The residual stress of milling varied slightly with the milling position. The small ratio of the tool diameter to the spot diameter may affect measurement accuracy. To this end, we selected three test points on each machined surface of the test piece. In addition, the distance between two adjacent points was $25 \mathrm{~mm}$, as shown in Figure 2. The residual stress average value at the three points was regarded as the milling-induced residual stress on the machined surface. An electrolytic polisher was used to polish the piece surface to obtain the residual stress distribution along the depth direction in the milled surface. The thickness of each polishing was $0.02 \mathrm{~mm}$ and the residual stress was measured layer by layer. A Kristall 650 electrolytic polishing machine maded in Germany was used for electrolytic polishing and the parameters are shown in Table 5. The residual stress distribution state corresponding to each milling parameter was obtained. We took the depth of the milling stress layer as the abscissa, and the residual stress value based on the experiment as the ordinate. Then, the spline function was employed for curve fitting in MATLAB. As a result, the residual stress distribution along the depth direction was obtained, as shown in Figures 3 and 4. The residual stress in the machined surface was the result of many factors. The experimental results showed that the end milling-induced residual stress was within $0.12 \mathrm{~mm}$ of the test piece surface, and the side milling-induced residual stress was within $0.08 \mathrm{~mm}$. The residual stress varied significantly along the depth direction, and the overall distribution was in a "spoon shape". After reaching the maximum value at a depth of $0.02 \mathrm{~mm}$, the residual stress gradually decreased with depth.

Table 3. The parameters of the side milling experiment.

\begin{tabular}{ccccc}
\hline Test Piece Number & $v_{c}(\mathbf{m} / \mathbf{m i n})$ & $f_{z}(\mathbf{m m})$ & $a_{p}(\mathbf{m m})$ & $a_{e}(\mathbf{m m})$ \\
\hline 1 & 125.6 & 0.01 & 15 & 0.2 \\
2 & 125.6 & 0.025 & 25 & 0.6 \\
3 & 125.6 & 0.05 & 35 & 1 \\
4 & 376.8 & 0.01 & 25 & 1 \\
5 & 376.8 & 0.025 & 35 & 0.2 \\
6 & 376.8 & 0.05 & 15 & 0.6 \\
7 & 628 & 0.01 & 35 & 0.6 \\
8 & 628 & 0.025 & 15 & 1 \\
9 & 628 & 0.05 & 25 & 2 \\
\hline
\end{tabular}

Table 4. XRD measurement parameters.

\begin{tabular}{cc}
\hline X-ray Diffraction Parameters & Specification/Values \\
\hline Tube type & $\mathrm{Cr}$ \\
Supplied current during the experiment & $6.7 \mathrm{~mA}$ \\
Supplied voltage during the experiment & $30 \mathrm{kV}$ \\
Exposure time for the calibration & $8 \mathrm{~s}$ \\
Exposure time for measurement & $10 \mathrm{~s}$ \\
Collimator diameter & $3 \mathrm{~mm}$ \\
Collimator distance & $10.390 \mathrm{~mm}$ \\
2-theta angle & $138.75^{\circ}$ \\
Tilt angle & $-45^{\circ}$ to $45^{\circ}$ \\
Number of tilts & $5 / 5$ \\
Rotation angle & $0^{\circ}$ to $90^{\circ}$ \\
Number of rotations & 2 \\
Stress resolution & $\pm 10 \mathrm{MPa}$ \\
Poisson ratio & 0.33 \\
Young's modulus & $70.3 \mathrm{GPa}$ \\
\hline
\end{tabular}

To conveniently analyze the influence of various milling parameters on residual stress, the residual stress at different depths under each group of parameters was equivalently treated using Equation (1). The results are listed in Tables 6 and 7. The maximum residual stress in the tables is $84.77 \mathrm{MPa}$, which is much smaller than the yield stress of the material, 
but will cause larger bending deformation of the weakly rigid thin-walled parts. The tool software, Design-Expert, was used for the variance analysis on the orthogonal data in Tables 6 and 7, and the results are shown in Tables 8 and 9. Generally, a $p$-value less than 0.05 indicates that the model term is significant, while a $p$-value greater than 0.1 indicates that the model term is not significant. The results in Table 8 suggest that $f_{z}$ is a significant model item for the feed direction of end milling, and $f_{z}$ and $v_{c}$ are significant model items for the vertical direction of feed of end milling.

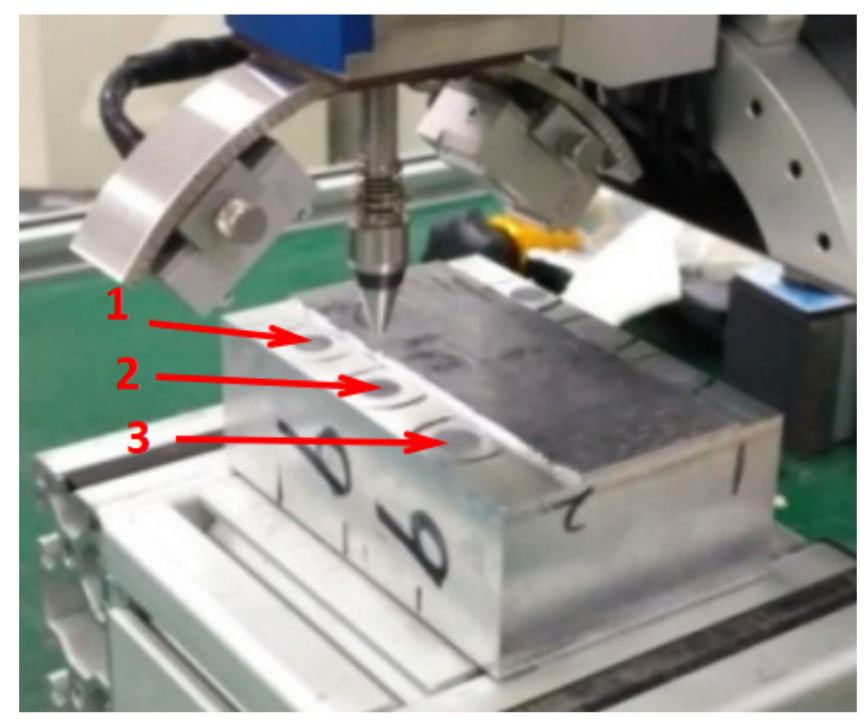

Figure 2. The three test points on the milled surface.

Table 5. Electrolytic polishing parameters.

\begin{tabular}{cc}
\hline Electrolytic Polishing Parameters & Specification/Values \\
\hline Electrolyte & $\mathrm{NaCl}$ \\
Voltage & $40 \mathrm{~V}$ \\
Flowrate & 10 \\
Working current & $2 \mathrm{~A}$ \\
Area & $63.59 \mathrm{~mm}^{2}$ \\
\hline
\end{tabular}

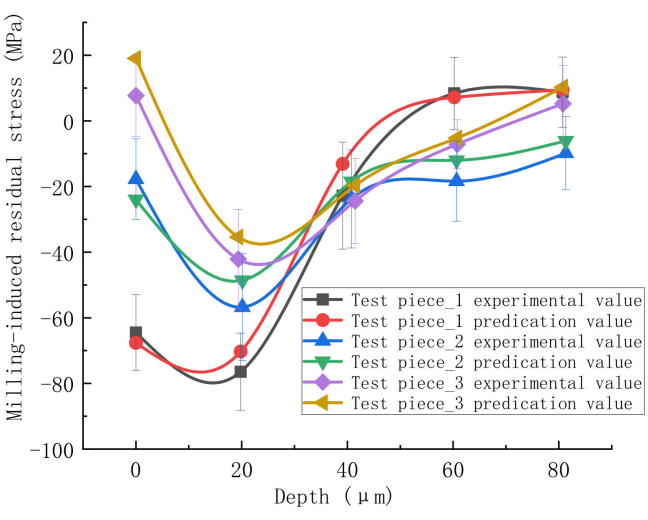

(a)

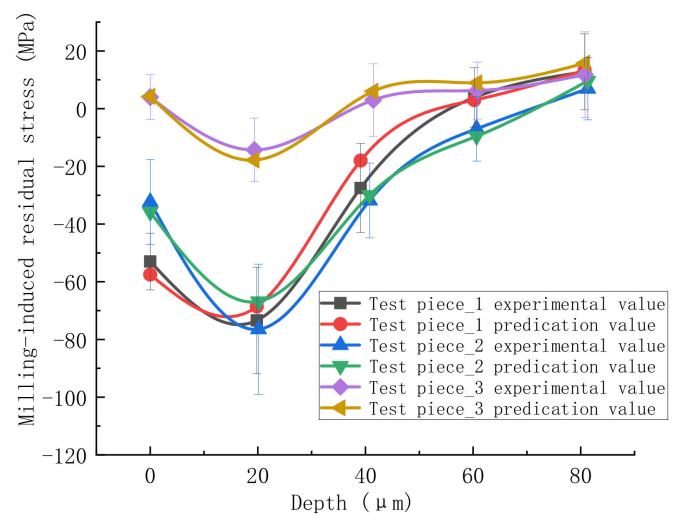

(b)

Figure 3. The residual stress distribution along the depth direction in the test piece surface of end milling: (a) the residual stress distribution in the feed direction; (b) the residual stress distribution in the vertical direction of feed. 


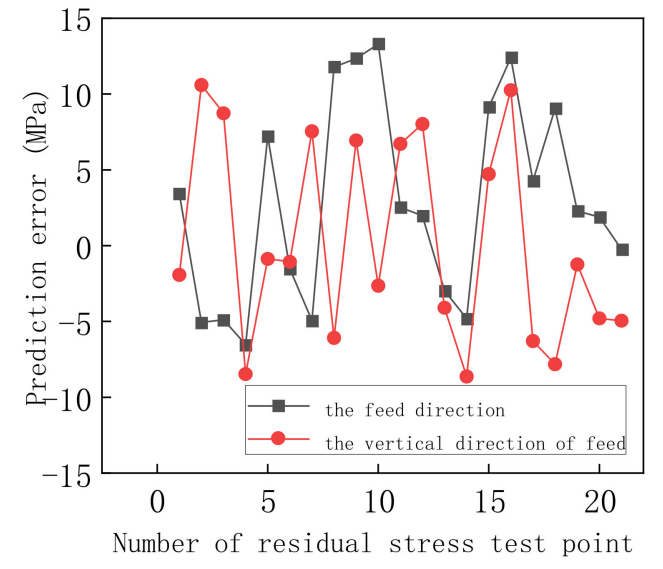

(a)

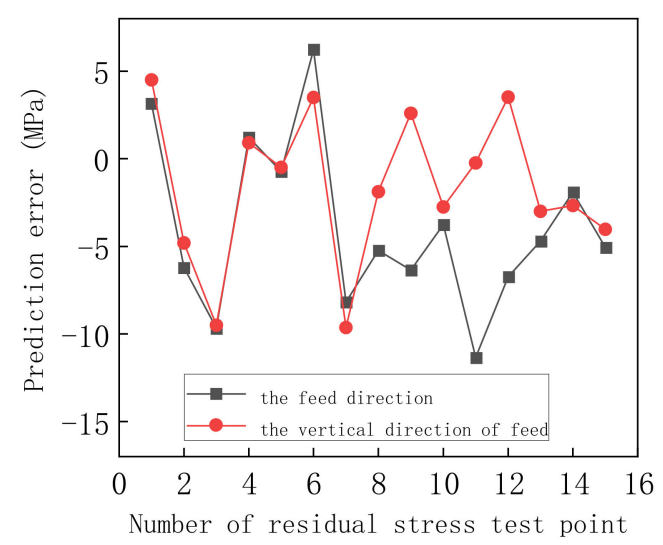

(b)

Figure 4. The residual stress distribution along the depth direction in the test piece surface of side milling: (a) the residual stress distribution in the feed direction; (b) the residual stress distribution in the vertical direction of feed.

Table 6. The equivalent results of the end milling-induced residual stress.

\begin{tabular}{ccccccc}
\hline Test Piece Number & $\begin{array}{c}\boldsymbol{v}_{c} \\
(\mathbf{m} / \mathbf{m i n})\end{array}$ & $\begin{array}{c}f_{z} \\
(\mathbf{m m} / \mathbf{z})\end{array}$ & $\begin{array}{c}\boldsymbol{a}_{\boldsymbol{p}} \\
(\mathbf{m m})\end{array}$ & $\begin{array}{c}\boldsymbol{a}_{\boldsymbol{e}} \\
(\mathbf{m m})\end{array}$ & $\begin{array}{c}\sigma_{\text {end } 1} \\
\mathbf{( M P a})\end{array}$ & $\begin{array}{c}\sigma_{\text {end } 2} \\
\mathbf{( M P a})\end{array}$ \\
\hline 1 & 125.6 & 0.01 & 0.50 & 10.00 & -84.77 & -67.56 \\
2 & 125.6 & 0.025 & 1.00 & 15.00 & -76.56 & -61.18 \\
3 & 125.6 & 0.05 & 1.50 & 20.00 & -60.34 & -36.40 \\
4 & 376.8 & 0.01 & 1.00 & 20.00 & -80.45 & -58.48 \\
5 & 376.8 & 0.025 & 1.50 & 10.00 & -52.16 & -48.36 \\
6 & 376.8 & 0.05 & 0.50 & 15.00 & -53.78 & -39.35 \\
7 & 628 & 0.01 & 1.50 & 15.00 & -77.18 & -38.26 \\
8 & 628 & 0.025 & 0.50 & 20.00 & -51.93 & -31.72 \\
9 & 628 & 0.05 & 1.00 & 10.00 & -41.43 & -36.46 \\
\hline
\end{tabular}

Table 7. The equivalent results of the side milling-induced residual stress.

\begin{tabular}{ccccccc}
\hline Test Piece Number & $\begin{array}{c}\boldsymbol{v}_{c} \\
(\mathbf{m} / \mathbf{m i n})\end{array}$ & $\begin{array}{c}f_{z} \\
(\mathbf{m m} / \mathbf{z})\end{array}$ & $\begin{array}{c}\boldsymbol{a}_{\boldsymbol{p}} \\
(\mathbf{m m})\end{array}$ & $\begin{array}{c}\boldsymbol{a}_{\boldsymbol{e}} \\
\mathbf{( m m )}\end{array}$ & $\begin{array}{c}\sigma_{\text {side } 1} \\
\mathbf{( M P a )}\end{array}$ & $\begin{array}{c}\sigma_{\text {side2 }} \\
\mathbf{( M P a})\end{array}$ \\
\hline 1 & 125.6 & 0.01 & 15.00 & 0.20 & -31.32 & -25.17 \\
2 & 125.6 & 0.025 & 25.00 & 0.60 & -18.65 & -12.17 \\
3 & 125.6 & 0.05 & 35.00 & 1.00 & -10.69 & -8.74 \\
4 & 376.8 & 0.01 & 25.00 & 1.00 & -17.34 & -10.40 \\
5 & 376.8 & 0.025 & 35.00 & 0.20 & -21.57 & -14.96 \\
6 & 376.8 & 0.05 & 15.00 & 0.60 & -27.22 & -16.17 \\
7 & 628 & 0.01 & 35.00 & 0.60 & -34.04 & -21.65 \\
8 & 628 & 0.025 & 15.00 & 1.00 & -19.96 & -18.86 \\
9 & 628 & 0.05 & 25.00 & 0.20 & -11.18 & -11.49 \\
\hline
\end{tabular}

Then, linear regression analysis was used to fit the empirical formula of the millinginduced residual stress of 7075 aluminum alloy. Through the orthogonal experiments, the exponential relationship between the residual stress and milling parameters was formulated as Equations (2)-(5).

$$
\sigma_{\text {equ }}=\int_{0}^{h} \sigma d h / H
$$

where $H$ is the depth of the milling-induced residual stress.

$$
\sigma_{\text {end } 1}=-38.0195 v_{c}^{-0.176} f_{z}^{-0.2827} a_{p}^{0.0108} a_{e}^{0.1732},
$$




$$
\sigma_{\text {end } 2}=-156.6478 v_{c}^{-0.2277} f_{z}^{-0.2081} a_{p}^{-0.0383} a_{e}^{-0.269},
$$

where $\sigma_{\text {end } 1}, \sigma_{\text {end } 2}$ denote the equivalent residual stress in the feed direction and vertical direction of feed of end milling, respectively; $125.6 \mathrm{~m} / \mathrm{min} \leq v_{c} \leq 628 \mathrm{~m} / \mathrm{min}$, $0.01 \mathrm{~mm} / \mathrm{z} \leq f_{z} \leq 0.05 \mathrm{~mm} / \mathrm{z}, 0.5 \mathrm{~mm} \leq a_{p} \leq 1.5 \mathrm{~mm}, 10 \mathrm{~mm} \leq a_{e} \leq 25 \mathrm{~mm}$.

$$
\begin{aligned}
& \sigma_{\text {side } 1}=-11.8627 v_{c}^{0.0577} f_{z}^{-0.3428} a_{p}^{-0.362} a_{e}^{-0.0843}, \\
& \sigma_{\text {side } 2}=-12.8353 v_{c}^{0.0947} f_{z}^{-0.2419} a_{p}^{-0.449} a_{e}^{-0.162},
\end{aligned}
$$

where $\sigma_{\text {side1 } 1}, \sigma_{\text {side2 }}$ denote the equivalent residual stress in the feed direction and vertical direction of feed of side milling, respectively; $125.6 \mathrm{~m} / \mathrm{min} \leq v_{c} \leq 628 \mathrm{~m} / \mathrm{min}$,

\begin{tabular}{|c|c|c|c|c|c|c|c|c|c|c|}
\hline \multirow{2}{*}{ Source } & \multicolumn{5}{|c|}{ The Feed Direction } & \multicolumn{5}{|c|}{ The Vertical Direction of Feed } \\
\hline & SS & df & MS & F-Value & $p$-Value & SS & df & MS & F-Value & $p$-Value \\
\hline Regression analysis & 1616.59 & 4 & 404.15 & 4.91 & 0.0762 & 1177.22 & 4 & 294.31 & 6.97 & 0.0433 \\
\hline Vc & 435.71 & 1 & 435.71 & 5.29 & 0.0829 & 574.28 & 1 & 574.28 & 13.59 & 0.0211 \\
\hline $\mathrm{fz}$ & 1146.41 & 1 & 1146.41 & 13.93 & 0.0203 & 451.56 & 1 & 451.56 & 10.69 & 0.0308 \\
\hline ap & 0.1067 & 1 & 0.1067 & 0.0013 & 0.973 & 40.61 & 1 & 40.61 & 0.9612 & 0.3824 \\
\hline ae & 34.37 & 1 & 34.37 & 0.4176 & 0.5534 & 110.77 & 1 & 110.77 & 2.62 & 0.1807 \\
\hline Residual & 329.24 & 4 & 82.31 & & & 169.01 & 4 & 42.25 & & \\
\hline Cor Total & 1945.83 & 8 & & & & 1346.23 & 8 & & & \\
\hline
\end{tabular}
$0.01 \mathrm{~mm} / \mathrm{z} \leq f_{z} \leq 0.05 \mathrm{~mm} / \mathrm{z}, 15 \mathrm{~mm} \leq a_{p} \leq 35 \mathrm{~mm}, 0.2 \mathrm{~mm} \leq a_{e} \leq 1 \mathrm{~mm}$.

Table 8. The results of analysis of variance in the orthogonal experiment of end milling.

\begin{tabular}{|c|c|c|c|c|c|c|c|c|c|c|}
\hline \multirow{2}{*}{ Source } & \multicolumn{5}{|c|}{ The Feed Direction } & \multicolumn{5}{|c|}{ The Vertical Direction of Feed } \\
\hline & SS & df & MS & F-Value & $p$-Value & SS & df & MS & F-Value & $p$-Value \\
\hline Regression analysis & 245.43 & 4 & 61.36 & 0.8409 & 0.5647 & 143.36 & 4 & 35.84 & 1.45 & 0.3638 \\
\hline Vc & 3.41 & 1 & 3.41 & 0.0467 & 0.8395 & 5.84 & 1 & 5.84 & 0.2363 & 0.6523 \\
\hline $\mathrm{fz}$ & 174.12 & 1 & 174.12 & 2.39 & 0.1973 & 69.84 & 1 & 69.84 & 2.83 & 0.1681 \\
\hline ap & 24.81 & 1 & 24.81 & 0.34 & 0.5911 & 36.75 & 1 & 36.75 & 1.49 & 0.2897 \\
\hline ae & 43.09 & 1 & 43.09 & 0.5906 & 0.4851 & 30.92 & 1 & 30.92 & 1.25 & 0.326 \\
\hline Residual & 291.87 & 4 & 72.97 & & & 98.88 & 4 & 24.72 & & \\
\hline Cor Total & 537.31 & 8 & & & & 242.24 & 8 & & & \\
\hline
\end{tabular}

Table 9. The results of analysis of variance in the orthogonal experiment of end milling.

The four formulas indicate that the equivalent residual stress in milling is expressed as compressive stress.

(1) The condition of end milling.

According to Equations (2) and (3), the significance of the milling parameters to the residual stress in the feed direction is $f_{z}>v_{c}>a_{e}>a_{p}$, and the significance of the parameters to the residual stress in the vertical direction of feed is $a_{e}>v_{c}>f_{z}>a_{p}$. When $v_{c}$ and $f_{z}$ increase, the residual stress in the two directions exhibits a decreasing trend. When $a_{p}$ and $a_{e}$ increase, the residual stress in the feed direction increases, and the residual stress in the vertical direction of feed decreases.

(2) The condition of side milling.

According to Equations (4) and (5), the significance of the parameters to the residual stress in the two directions is $a_{p}>f_{z}>a_{e}>v_{c}$. When $n$ increases, the residual stress in the two directions increases. When $f_{z}, a_{p}$ and $a_{e}$ increase, the residual stress in the two directions decreases.

Note that, except for Equation (2), the $p$-values of the other three equations are all greater than 0.05 . It shows that the regression effect is not significant. Thus, it is necessary to develop better analysis methods. 


\section{Prediction Model of Milling-Induced Residual Stress}

\subsection{Formulation of BP Neural Network}

The BP neural network model consists of an input layer, a hidden layer and an output layer. The function of newff $($ ) is used to formulate the model, expressed as:

$$
\text { net }=\operatorname{newff}(\mathrm{PR},[\mathrm{S} 1 \mathrm{~S} 2 \ldots \mathrm{SN}],\{\mathrm{TF} 1 \mathrm{TF} 2 \ldots \mathrm{TFN}\}, \mathrm{BTF}, \mathrm{BLF}, \mathrm{PF}),
$$

where PR denotes a matrix of $\mathrm{R} \times 2$ to define the value range of $\mathrm{R}$ number of input vectors; [S1 S2 ... SN] is the number of neurons in each layer of the neural network; \{TF1 TF2 ... TFN\} represents the transfer function of each layer; by default, "tansig" and "purelin" are the transfer functions of the hidden layer and output layer, respectively; BLF reflects the learning of weights/thresholds, using the "learngdm" function; PF is the performance function, using the "mse" function. The input sample is transferred to PR after normalization, and PR is written as minmax(inputn).

This study involves five factors: cutting speed, feed per tooth, back-cutting, cutting width, and milling stress layer depth. Modeling mainly considers the relationship between the five factors and the milling-induced residual stress. Thus, the input layer is designed with five neurons, corresponding to the five factors. The output layer has one neuron corresponding to the residual stress. The three-layer BP neural network with a hidden layer is used to predict the workpiece residual stress. By changing the number of neurons in the hidden layer, the error of the training process under different numbers is comparatively analyzed. Based on the principle of minor error, the number of hidden layer neurons is determined as fifteen. Thus, the function is formulated as Equation (7).

$$
\text { net } \left.=\text { newff(minmax(inputn), [15 1], }\left\{{ }^{\prime} \tan \operatorname{sig}^{\prime}, \text { purelin }^{\prime}\right\}, \text { ' traingdx }{ }^{\prime},{ }^{\prime} \text { learngdm }{ }^{\prime \prime} \mathrm{mse}^{\prime}\right) \text {, }
$$

The specific operation steps of the BP neural network are as follows:

Step 1: network initialization. Each connection weight is assigned a random number in the interval $[-1,1]$; the error function $e$, calculation accuracy $\varepsilon$, and maximum learning times $M$ are given.

Step 2: the input and output of the hidden layer and output layer are calculated as

$$
h i_{p}(k)=\sum_{i=1}^{5} \mathrm{w}_{h i} \mathrm{x}_{i}(k)+\mathrm{b}_{p},
$$

where $p$ is the number of hidden layers, $p=1,2, \ldots, 15 ; i$ is the number of input variables, $h=1,2,3, \ldots, p ; k$ is the number of samples, $k=1,2, \ldots, 63$ represents 63 samples of end milling; $h i_{p}(k)$ is the input of the hidden layer; $\mathrm{w}_{h i}$ is the connection weight between the input layer and the hidden layer; $b_{p}$ denotes the threshold of the hidden layer.

$$
h o_{p}(k)=\operatorname{tansig}\left(h i_{p}(k)\right)
$$

where $h o_{p}(k)$ is the output of the hidden layer.

$$
y i(k)=\sum_{p=1}^{15} w_{h o} h o_{p}(k)+\mathrm{b}_{\mathrm{o}},
$$

where $y i(k)$ is the input of the output layer, $w_{o h}$ is the connection weight between the hidden layer and the output layer, and $b_{o}$ is the threshold of the output layer.

$$
y o(k)=\operatorname{purelin}(y i(k)),
$$

where $y_{o}(k)$ is the output of the output layer.

Step 3: the partial derivative $\delta_{o}(k)$ of the error function to each neuron in the output layer is calculated as:

$$
\frac{\partial e}{\partial w_{o h}}=\frac{\partial e}{\partial y i} \frac{\partial y i}{\partial w_{o h}}
$$




$$
\begin{gathered}
\frac{\partial y i}{\partial w_{o h}}=\frac{\partial\left(\sum_{h}^{15} w_{o h} h o_{h}(k)-b_{0}\right)}{\partial w_{o h}}=h o_{h}(k), \\
\frac{\partial e}{\partial y i}=\frac{\partial\left(\frac{1}{2}\left(d_{o}(k)-y o(k)\right)\right)^{2}}{\partial y i}=-\left(d_{o}(k)-y o(k)\right) \operatorname{purelin} /\left(y i(k)-\delta_{0}(k),\right.
\end{gathered}
$$

where $d_{o}(k)$ represents the expected output.

$$
\frac{\partial e}{\partial h i_{h}(k)}=-\delta_{o}(k) w_{h o} \operatorname{tansig}\left(h i_{p}(k)\right) \triangleq-\delta_{h}(k),
$$

Step 4: the connection weight $\Delta w_{o h}(k)$ is modified using $\delta_{o}(k)$ of each neuron in the output layer and the output of each neuron in the hidden layer.

$$
\Delta w_{o h}(k)=-\mu \frac{\partial e}{\partial w_{o h}}=\mu \delta_{o}(k) h o_{h}(k),
$$

where $\mu$ is the given learning rate.

$$
w_{o h}^{N+1}=w_{o h}^{N}+\mu \delta_{o}(k) h o_{h}(k),
$$

Step 5: the connection weight $\Delta w_{i h}(k)$ is modified using $\delta_{h}(k)$ of each neuron in the hidden layer and the input of each neuron in the input layer.

$$
\begin{aligned}
\Delta w_{h i}(k)=-\mu \frac{\partial e}{\partial w_{h i}} & =-\mu \frac{\partial e}{\partial h i_{h}(k)} \frac{\partial h i_{h}(k)}{\partial w_{h i}}=\delta_{h}(k) x_{i}(k), \\
w_{h i}^{N+1} & =w_{h i}^{N}+\mu \delta_{h}(k) x_{i}(k),
\end{aligned}
$$

Step 6: the global error is calculated as:

$$
E=\frac{1}{126} \sum_{k=1}^{63}\left(d_{o}(k)-y_{o}(k)\right)^{2},
$$

Step 7: Convergence judgment. If the error requirements are met and the maximum number of training times is reached, the learning ends; otherwise, the next learning cycle starts.

To investigate the performance of the formulated neural network, we implemented predictions based on the training data and observe the errors of the prediction model. The prediction results are shown in Figure 5. The results show that the prediction results obtained from the BP neural network are not ideal. The error on several samples is significant, and the absolute error exceeds $20 \mathrm{MPa}$. It is because the BP neural network may converge to a local minimum.

\subsection{BP Neural Network Optimized by Genetic Algorithm}

To deal with the problem of BP neural network converging to a local minimum, this study uses the genetic algorithm to optimize the neural network, thereby improving the convergence speed and reducing the prediction error. After optimization using the genetic algorithm, the weights and thresholds of the data in the end milling and side milling are obtained. The BP neural network prediction model is determined accordingly. We used the optimized model to implement predictions based on the training data. The prediction results are shown in Figure 6. The absolute error of the optimized prediction model is within $\pm 6 \mathrm{MPa}$, which is consistent with the expected output. This verifies the effectiveness of the genetic algorithm for optimizing neural networks. 


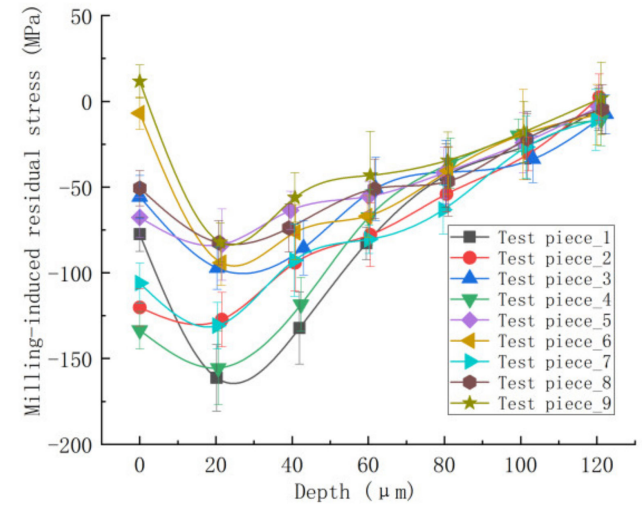

(a)

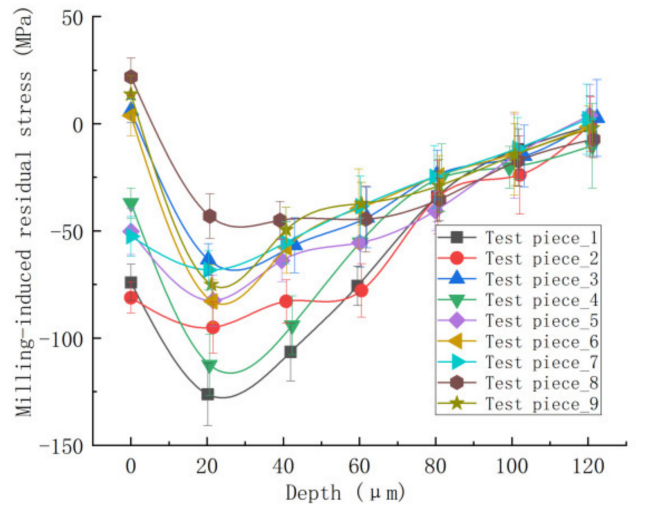

(b)

Figure 5. The prediction results of the BP neural network: (a) the prediction results; (b) the prediction error.

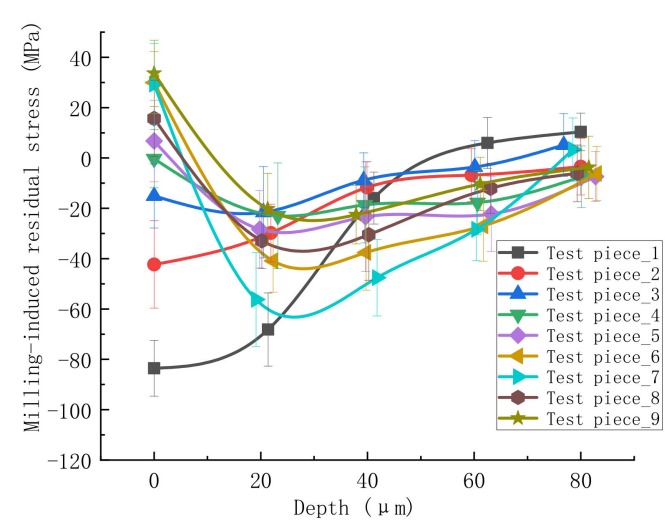

(a)

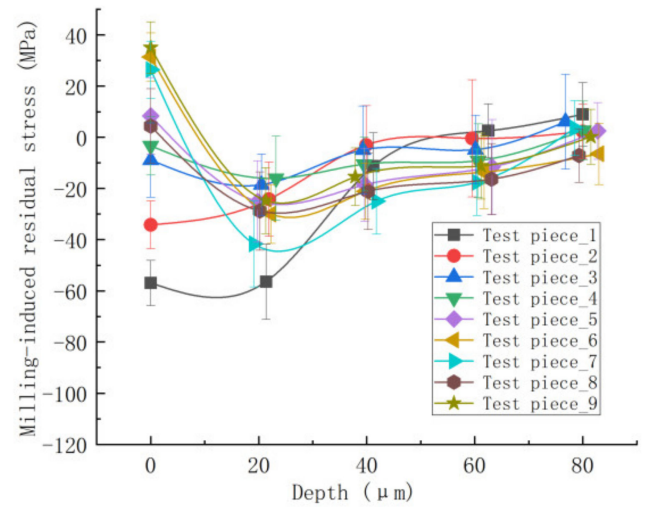

(b)

Figure 6. The prediction results of the BP neural network optimized by genetic algorithm: (a) the prediction results; (b) the prediction error.

\subsection{Validation of BP Neural Network Model}

To verify the accuracy of the residual stress prediction model, six groups of data were re-selected for the milling experiment, three groups for end milling and three groups for side milling. The experimental parameters are listed in Tables 10 and 11, and the results are shown in Figures 7-9. Figures 7 and 8 show that the residual stress distribution curve obtained by the prediction model is consistent with the curve measured by the experiment. Figure 9 presents that the residual stress prediction absolute error of end milling is between 0.24-13.30 MPa, and that of side milling is between $0.23-11.34 \mathrm{MPa}$. The prediction error is in the same order of magnitude (i.e., $\pm 10 \mathrm{MPa}$ ) as the measurement accuracy of the residual stress analyzer used. Therefore, the proposed prediction model of milling-induced residual stress is accurate.

Table 10. The experimental parameters for the validation of residual stress prediction model in the end milling.

\begin{tabular}{ccccc}
\hline Test Piece Number & $v_{c}(\mathbf{m} / \mathbf{m i n})$ & $f_{z}(\mathbf{m m} / \mathbf{z})$ & $a_{p}(\mathbf{m m})$ & $a_{e}(\mathbf{m m})$ \\
\hline 1 & 188.4 & 0.04 & 0.5 & 15 \\
2 & 251.2 & 0.02 & 1.2 & 12 \\
3 & 376.8 & 0.04 & 0.6 & 13 \\
\hline
\end{tabular}


Table 11. The experimental parameters for the validation of residual stress prediction model in the side milling.

\begin{tabular}{ccccc}
\hline Test Piece Number & $v_{c}(\mathbf{m} / \mathbf{m i n})$ & $f_{z}(\mathbf{m m} / \mathbf{z})$ & $a_{p}(\mathbf{m m})$ & $a_{e}(\mathbf{m m})$ \\
\hline 1 & 188.4 & 0.01 & 15 & 0.2 \\
2 & 251.2 & 0.02 & 18 & 0.5 \\
3 & 376.8 & 0.03 & 24 & 0.9 \\
\hline
\end{tabular}

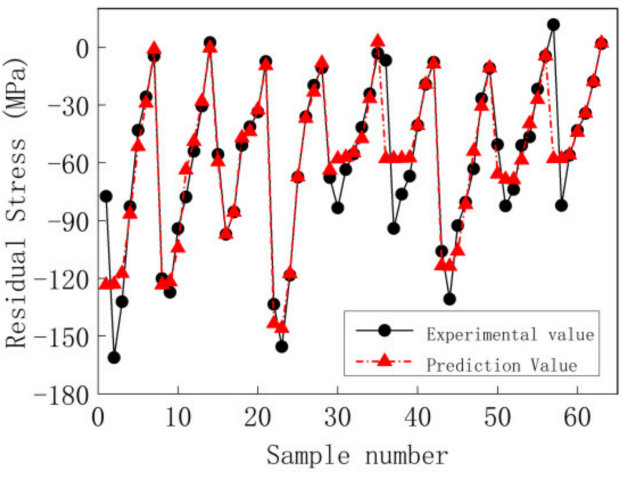

(a)

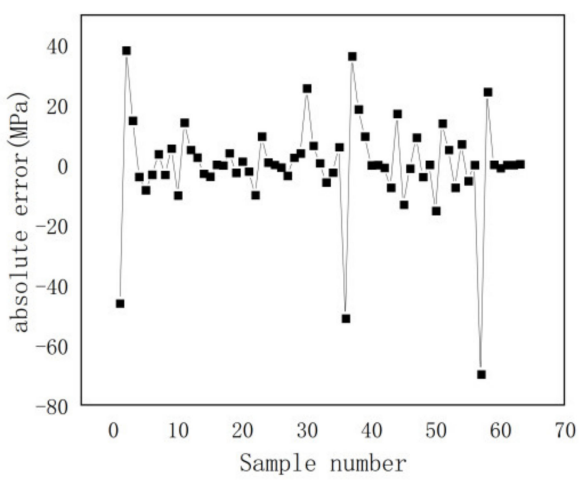

(b)

Figure 7. The end milling experimental results: (a) the validation of prediction model in the feed direction; (b) the validation of prediction model in the vertical direction of feed.

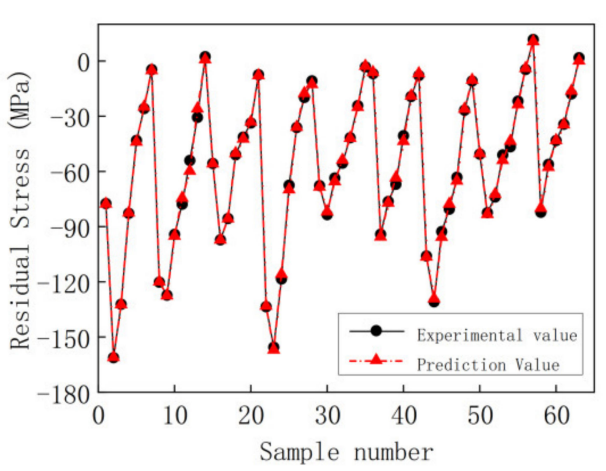

(a)

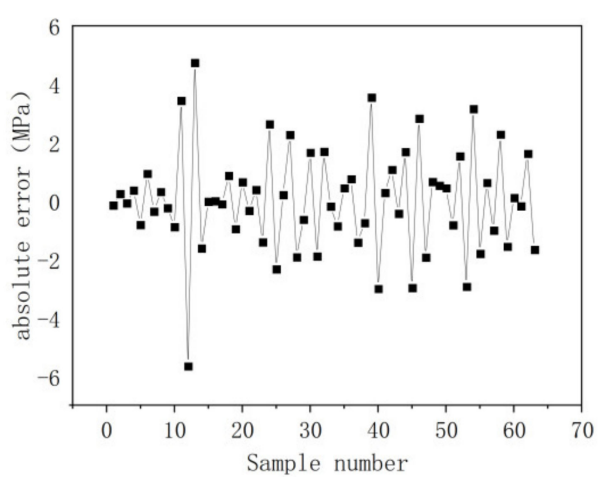

(b)

Figure 8. The side milling experimental results: (a) the validation of prediction model in the feed direction; (b) the validation of prediction model in the vertical direction of feed.

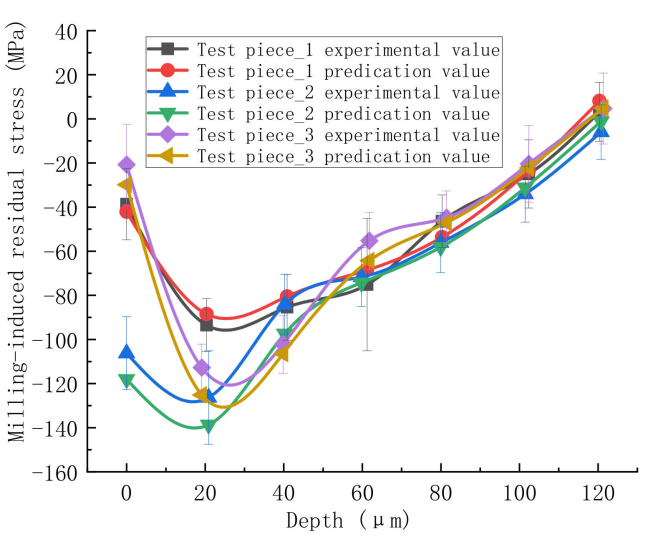

(a)

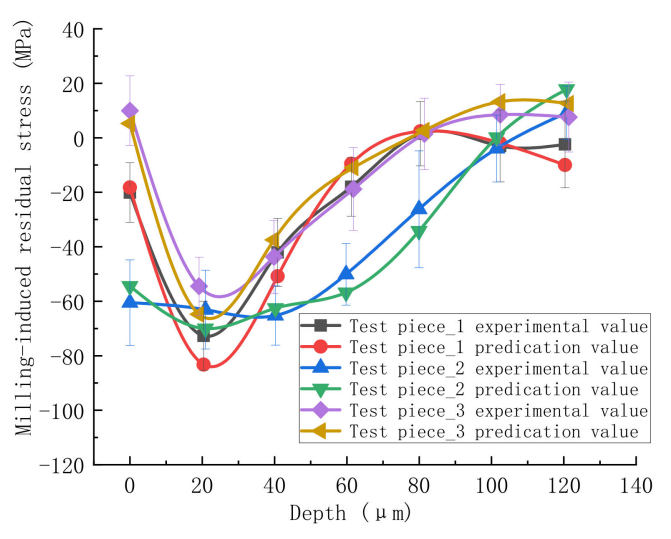

(b)

Figure 9. The prediction error: (a) the prediction error of the end milling prediction model; (b) the prediction error of the side milling prediction model. 


\section{Conclusions}

This paper studies the influence of milling parameters on the residual stress of 7075 aluminum alloy and formulates a residual stress prediction model related to the parameters. It provides a calculation tool for obtaining milling-induced residual stress. First, the orthogonal experiment is designed to implement milling experiments on 7075 aluminum alloy. Through electrolytic polishing and X-ray diffraction, layer by layer, the workpiece residual stress distribution at different depths was obtained. Secondly, the residual stress characterization equations related to the milling parameters in end milling and side milling are formulated based on regression analysis. The sensitivity coefficient of each milling parameter to the residual stress is calculated. Thirdly, the prediction model of milling-induced residual stress is proposed based on experimental data, using a genetic algorithm and BP neural network. The findings indicate that milling-induced residual stress varies significantly along the workpiece depth direction. The residual stress depth is within $0.12 \mathrm{~mm}$ of the workpiece surface, and the overall distribution is in a "spoon shape". The proposed prediction model can calculate the residual stress under different milling parameters. The prediction error is between 0-14 MPa, roughly the same as the measurement accuracy of the residual stress analyzer. Therefore, the prediction model has high accuracy and powerful application potential. In addition, this study gives constant values to factors, such as cutting tools, workpiece materials, and cooling conditions, resulting in limitations in the prediction model. In the future, we will incorporate more factors affecting milling-induced residual stress into the prediction model to improve its generality. In addition, the reverse approach of the optimal machining plan under the specified residual stress will be our research focus.

\section{Replication of Results}

In order to facilitate the reproduction of results presented in this paper, the MATLAB code is provided as the Supplementary Materials. The basic information of the code files is listed in Table 12. The detailed description is written as the comments in corresponding files. Notes that, the program package of 'bcs_BP.rar' needs to be extracted into a folder, which should be added into the search path of MATLAB.

Table 12. The code files in the Supplementary Materials.

\begin{tabular}{|c|c|}
\hline Filename & Description \\
\hline ED-RS.xlsx & Experimental data on residual stress \\
\hline VD-RS.xlsx & Verification data of residual stress experiment \\
\hline P_ESRS.m & Calculation program of equivalent side milling residual stress \\
\hline P_EERS.m & Calculation program of equivalent end milling residual stress \\
\hline Basic data for(eq.2-eq.5).xlsx & Basic data for Equations (2)-(5) \\
\hline CC_EQ2_3.m & Procedure for calculating the coefficients and exponents of Equations (2) and (3) \\
\hline CC_EQ4_5.m & Procedure for calculating the coefficients and exponents of Equations (4) and (5) \\
\hline Main_BP_TP_E_FD.m & Training program of BP neural network for residual stress in feed direction in end milling mode \\
\hline Main_BP_TP_E_VFD.m & $\begin{array}{l}\text { Training program of BP neural network for residual stress in vertical feed direction in end } \\
\text { milling mode }\end{array}$ \\
\hline Main_BP_TP_S_FD.m & Training program of BP neural network for residual stress in feed direction in side milling mode \\
\hline Main_BP_TP_S_VFD.m & $\begin{array}{c}\text { Training program of BP neural network for residual stress in vertical feed direction in side } \\
\text { milling mode }\end{array}$ \\
\hline Main_BP_PP_E_FD.m & BP neural network prediction program for residual stress in feed direction in end milling mode \\
\hline Main_BP_PP_E_VFD.m & $\begin{array}{c}\text { BP neural network prediction program for residual stress in vertical feeding direction in end } \\
\text { milling mode }\end{array}$ \\
\hline Main_BP_PP_S_FD.m & BP neural network prediction program for residual stress in feed direction in side milling mode \\
\hline Main_BP_PP_S_VFD.m & $\begin{array}{c}\text { BP neural network prediction program for residual stress in vertical feeding direction in side } \\
\text { milling mode }\end{array}$ \\
\hline BP-END-feed direction.rar & Summary of BP neural network program for residual stress in the feed direction of end milling \\
\hline BP-END-vertical feed direction.rar & $\begin{array}{c}\text { Summary of BP neural network program for residual stress in the vertical feed direction of } \\
\text { end milling }\end{array}$ \\
\hline BP-SIDE-feed direction.rar & Summary of BP neural network program for residual stress in the feed direction of side milling \\
\hline BP-SIDE-vertical feed direction.rar & $\begin{array}{l}\text { Summary of BP neural network program for residual stress in the vertical feed direction of } \\
\text { side milling }\end{array}$ \\
\hline
\end{tabular}


Supplementary Materials: The following are available online at https://www.mdpi.com/article/10 .3390/app11135881/s1.

Author Contributions: Conceptualization, S.Y. and Y.W.; data analysis, S.Y. and H.G.; formula derivation, S.Y.; chart processing, C.P.; programming, Y.W.; funding acquisition, Y.W.; investigation, S.Y.; methodology, S.Y.; project administration, H.G.; resources, Y.W.; software, C.P.; validation, C.P. and Y.H.; writing-original draft, S.Y.; writing-review and editing, H.G. All authors have read and agreed to the published version of the manuscript.

Funding: This research was funded by the National Natural Science Foundation of China (Grant Number 51327902).

Institutional Review Board Statement: Not applicable.

Informed Consent Statement: Not applicable.

Data Availability Statement: Data are contained within the article.

Conflicts of Interest: The authors declare no conflict of interest.

\section{References}

1. Duan, Z.; Li, C.; Ding, W.; Zhang, Y.; Yang, M.; Gao, T.; Cao, H.; Xu, X.; Wang, D.; Mao, C.; et al. Milling Force Model for Aviation Aluminum Alloy: Academic Insight and Perspective Analysis. Chin. J. Mech. Eng. 2021, 34, 18. [CrossRef]

2. Li, H.; Jia, L.; Huang, J.; Ma, Y. Precipitation behavior and properties of extruded 7136 aluminum alloy under different aging treatments. Chin. J. Aeronaut. 2021, 34, 612-619. [CrossRef]

3. Chatterjee, B.; Bhowmik, S. Evolution of material selection in commercial aviation industry-A review. Sustain. Eng. Prod. Manuf. Technol. 2019, 199-219. [CrossRef]

4. Ji, M.; Li, W.; Liu, H.; Zhu, L.; Chen, H.; Li, W. Effect of titanium sol on sulfuric-citric acids anodizing of 7150 aluminum alloy. Surf. Interfaces 2020, 19, 100479. [CrossRef]

5. He, S.; Chen, S.; Zhao, Y.; Qi, N.; Zhan, X. Study on the intelligent model database modeling the laser welding for aerospace aluminum alloy. J. Manuf. Process. 2021, 63, 121-129. [CrossRef]

6. Zhang, J.; Cheng, X.; Xia, Q.; Yan, C. Strengthening effect of laser shock peening on 7075-T6 aviation aluminum alloy. Adv. Mech. Eng. 2020, 12, 1687814020952177. [CrossRef]

7. Zhong, H.; Liu, Z.; Qin, H.; Liu, Y. Static analysis of thin-walled space frame structures with arbitrary closed cross-sections using transfer matrix method. Thin Walled Struct. 2018, 123, 255-269. [CrossRef]

8. Sedeh, M.R.N.; Ghaei, A. The effects of machining residual stresses on springback in deformation machining bending mode. Int. J. Adv. Manuf. Technol. 2021, 114, 1087-1098. [CrossRef]

9. Sahraei, A.; Pezeshky, P.; Sasibut, S.; Rong, F.; Mohareb, M. Closed form solutions for shear deformable thin-walled beams including global and through-thickness warping effects. Thin Walled Struct. 2021, 158, 107190. [CrossRef]

10. Singh, A.; Agrawal, A. Comparison of deforming forces, residual stresses and geometrical accuracy of deformation machining with conventional bending and forming. J. Mater. Process. Technol. 2016, 234, 259-271. [CrossRef]

11. Santos, M.C.; Machado, A.R.; Sales, W.F.; Barrozo, M.A.S.; Ezugwu, E.O. Machining of aluminum alloys: A review. Int. J. Adv. Manuf. Technol. 2016, 86, 3067-3080. [CrossRef]

12. Ruitao, P.; Linfeng, Z.; Jiawei, T.; Xiuli, F.; Meiliang, C. Application of pre-stressed cutting to aviation alloy: The effect on residual stress and surface roughness. J. Manuf. Process. 2021, 62, 501-512. [CrossRef]

13. Zhang, Z.; Luo, M.; Tang, K.; Zhang, D. A new in-processes active control method for reducing the residual stresses induced deformation of thin-walled parts. J. Manuf. Process. 2020, 59, 316-325. [CrossRef]

14. Li, J.G.; Wang, S.Q. Distortion caused by residual stresses in machining aeronautical aluminum alloy parts: Recent advances. Int. J. Adv. Manuf. Technol. 2017, 89, 997-1012. [CrossRef]

15. Guo, J.; Fu, H.; Pan, B.; Kang, R. Recent progress of residual stress measurement methods: A review. Chin. J. Aeronaut. 2021, 34, 54-78. [CrossRef]

16. Mirkoohi, E.; Bocchini, P.; Liang, S.Y. Inverse analysis of residual stress in orthogonal cutting. J. Manuf. Process. 2019, 38, 462-471. [CrossRef]

17. Shan, C.; Zhang, M.; Zhang, S.; Dang, J. Prediction of machining-induced residual stress in orthogonal cutting of Ti6Al4V. Int. J. Adv. Manuf. Technol. 2020, 107, 2375-2385. [CrossRef]

18. Shen, Q.; Liu, Z.; Hua, Y.; Zhao, J.; Lv, W.; Hassan Mohsan, A.U. Effects of cutting edge micro-geometry on residual stress in orthogonal cutting of Inconel 718 by FEM. Materials 2018, 11, 1015. [CrossRef]

19. Ji, C.; Sun, S.; Lin, B.; Fei, J. Effect of cutting parameters on the residual stress distribution generated by pocket milling of 2219 aluminum alloy. Adv. Mech. Eng. 2018, 10, 1687814018813055. [CrossRef]

20. Liu, X.; Xiong, R.; Xiong, Z.; Zhang, S.; Zhao, L. Simulation and experimental study on surface residual stress of ultra-precision turned 2024 aluminum alloy. J. Braz. Soc. Mech. Sci. Eng. 2020, 42, 1-7. [CrossRef] 
21. Salvati, E.; Korsunsky, A.M. A simplified FEM eigenstrain residual stress reconstruction for surface treatments in rbitrary 3D geometries. Int. J. Mech. Sci. 2018, 4, 138-139.

22. Meng, L.; Khan, A.M.; Zhang, H.; Fang, C.; He, N. Research on surface residual stresses generated by milling Ti6Al4V alloy under different pre-stresses. Int. J. Adv. Manuf. Technol. 2020, 107, 2597-2608. [CrossRef]

23. Zhang, S.; Gong, M.; Zeng, X.; Gao, M. Residual stress and tensile anisotropy of hybrid wire arc additive-milling subtractive manufacturing. J. Mater. Process. Technol. 2021, 293, 117077. [CrossRef]

24. Xiong, Y.; Wang, W.; Shi, Y.; Jiang, R.; Shan, C.; Liu, X.; Link, K. Investigation on surface roughness, residual stress and fatigue property of milling in-situ $\mathrm{TiB}_{2} / 7050 \mathrm{Al}$ metal matrix composites. Chin. J. Aviat. 2021, 34, 451-464. [CrossRef]

25. Huang, X.; Zhang, X.; Leopold, J.; Ding, H. Analytical Model for Prediction of Residual Stress in Dynamic Orthogonal Cutting Process. ASME J. Manuf. Sci. Eng. 2018, 140, 011002. [CrossRef]

26. Cheng, M.; Jiao, L.; Yan, P.; Feng, L.; Qiu, T.; Wang, X.; Zhang, N. Prediction of surface residual stress in end milling with Gaussian process regression. Measurement 2021, 178, 109333. [CrossRef]

27. Vovk, A.; Sölter, J.; Karpuschewski, B. Finite element simulations of the material loads and residual stresses in milling utilizing the CEL method. Procedia CIRP 2020, 87, 539-544. [CrossRef]

28. Zhou, R.; Yang, W. Analytical modeling of machining-induced residual stresses in milling of complex surface. Int. J. Adv. Manuf. Technol. 2019, 105, 565-577. [CrossRef]

29. Reimer, A.; Luo, X. Prediction of residual stress in precision milling of AISI H13 steel. Procedia CIRP 2018, 71, 329-334. [CrossRef]

30. Morin, L.; Braham, C.; Tajdary, P.; Seddik, R.; Gonzalez, G. Reconstruction of heterogeneous surface residual-stresses in metallic materials from X-ray diffraction measurements. Mech. Mater. 2021, 158, 103882. [CrossRef] 